\title{
Viver em tempos sombrios: a experiência e os laços com os contemporâneos
}

(Living in gloomy times: experience and bonds with our contemporaries)

(Vivir en tiempos sombríos: la experiencia y los vínculos con los contemporáneos)

\author{
Miriam Debieux Rosa* \\ Maria Cristina Vicentin ${ }^{* *}$ \\ Viviani S. C. Catroli***
}

\begin{abstract}
Resumo
neste artigo, vamos examinar, apoiadas em convergências ético-políticas de autores de diversas áreas de conhecimento, as estratégias de poder e os impasses do sujeito contemporâneo nestes tempos sombrios. Apontaremos algumas das consequências desse poder para o sujeito no capitalismo avançado, particularmente as que incidem sobre o sentido da vida, sobre a historização do sujeito. Indicaremos algumas modalidades de resistência que supóem o deslocamento do gozo monitorado politicamente e mortífero para o desejo, para uma práxis caracterizada pelo resgate da experiência compartilhada do mundo, em que os processos coletivos e a reabilitação do espaço público possam tornar possível a construção de projetos comuns. $\mathrm{O}$ artigo recoloca a noção de contemporâneo pela via da conjugação de diversas temporalidades, afirmando a construção de um modo particular de atribuir sentido ao presente. Entende que, resgatando a experiência compartilhada com os contemporâneos, podese reinventar a vida e criar mecanismos de pressão contra a submissão ao poder soberano.
\end{abstract}

Palavras-chave: contemporâneo; experiência; psicanálise; resistência; política.

\begin{abstract}
Based on ethical and political viewpoints of authors from various fields and on psychoanalysis, this article examines power strategies and the contemporary subject's predicaments in these gloomy times.
\end{abstract}

\footnotetext{
* Texto recebido em outubro/2008 e aprovado para em maio/2009.

* Psicanalista, professora doutora do Programa de Psicologia Clínica da USP, onde coordena o Laboratório Psicanálise e Sociedade - PUC SP, e-mail: debieux@terra.com.br

** Psicóloga, professora doutora do Programa de Pós-Graduação da Psicologia Social da PUC-SP, e-mail: crisvic1@uol.com.br

*** Psicóloga clínica, doutoranda em Psicologia Social pela PUC-SP; doutoranda em Sciences de L'Education (co-tutela) pela Universidade Paris 8 - Vincennes / Saint-Denis - PUC SP, e-mail: vivianisc@gmail.com
} 
It points out some of the consequences of power to the subject of today's advanced capitalism, particularly those affecting life's meaning and history. It indicates some means of resistance that entail the displacement of a politically monitored jouissance, lethal to desire, onto a praxis characterized by the rescue of a shared world experience, in which collective processes and the rehabilitation of public spaces may enable the construction of common projects. The article reshapes the notion of contemporariness by connecting several temporalities, thus asserting the construction of an individual way of ascribing meaning to the present. It demonstrates that, by rescuing the experience with one's contemporaries, it is possible to reinvent life and create pressure mechanisms against submission to a sovereign power.

Key words: Contemporariness; Experience; Psychoanalysis; Resistance; Politics.

\section{Resumen}

En este artículo vamos a examinar, apoyados en autores de diversas áreas y en el psicoanálisis, las estrategias de poder y los impasses del sujeto contemporáneo en estos tiempos sombríos. Apuntaremos algunas consecuencias de este poder para el sujeto en el capitalismo avanzado, particularmente aquellas que inciden sobre el sentido de la vida y la historicidad del sujeto. Indicaremos algunas modalidades de resistencia que suponen el desplazamiento del gozo monitorizado políticamente, mortífero para el deseo, para una praxis que rescate la experiencia compartida del mundo, donde los procesos colectivos y la rehabilitación del espacio público posibiliten la construcción de proyectos en común. El artículo recoloca la noción de contemporáneo vía la conjugación de diversas temporalidades, afirmando la construcción de un modo particular de atribuir sentido al presente. Entiende que rescatando la experiencia compartida con los contemporáneos, se puede reinventar la vida y crear mecanismos de presión contra la sumisión al poder soberano.

Palabras clave: contemporáneo, experiencia, psicoanálisis, resistencia, política.

Esta reflexão foi escrita em agradecimento àqueles que me ajudam a manter a esperança, em especial aos meus contemporâneos: "Quem são os meus contemporâneos? - pergunta-se Juan Gelman. Juan diz que, às vezes, encontra homens que têm cheiro de medo, em Buenos Aires, em Paris ou em qualquer lugar, e sente que esses homens não são seus contemporâneos. Mas existe um chinês que, há milhares de anos, escreveu um poema, sobre um pastor de cabras que está longe, muito longe da mulher amada, e, 
mesmo assim, pode escutar, no meio da noite, no meio da neve, o rumor do pente em seus cabelos; e lendo este poema remoto, Juan comprova que sim, que eles sim: que esse poeta, esse pastor e essa mulher são seus contemporâneos." (Galeano, 2002, p.242.)

$\mathrm{N}$ este trabalho, vamos examinar, apoiadas em convergências ético-políticas de autores de diversas áreas de conhecimento, as estratégias de poder e os impasses do sujeito contemporâneo nestes tempos sombrios em que a felicidade segue o imperativo do gozo, mortífero para o desejo, aproximando vida e morte, ou pior, mais da morte do que da vida. Apontaremos algumas das consequências para o sujeito no capitalismo avançado, particularmente as que incidem sobre o sentido da vida, a relativização da existência compartilhada e a fragilização da experiência que marca a historicização do sujeito. Indicaremos algumas modalidades de resistência que barram essas estratégias.

Há estratégias e consequências do capitalismo avançado para o sujeito, particularmente afetado pelo atravessamento da lei do mercado na lei do desejo. Os discursos que daí decorrem incitam a um modo de laço que empurra o sujeito violentamente ao gozo ${ }^{1}$, seja sob a forma de consumo e lucro, seja na forma de sofrimento (Rosa, Carignato \& Berta, 2006).

Discurso refere-se a como se tecem as relações sociais e o que produzem como efeito. Lacan (1969-1970/1992) chamou de discurso os laços sociais tecidos e estruturados pela linguagem. O discurso do mestre é aquele no qual o poder faz laço social entre aquele que manda e aquele que trabalha. É o laço que permite governar. Lacan baseou-se na dialética do senhor e do escravo tal como apresentada por Hegel na elucidação da constituição da consciência de si. Nesta, há uma articulação entre o desejo de um com o desejo do outro, entre a vida e a morte, entre o objeto e o gozo. Nesse discurso, o saber transformador representado pelo trabalho está do lado do escravo, embora ele não saiba disso, pois o mestre dita o que é a realidade, afirmando-a como verdade.

O discurso do capitalismo, em que a lógica do capital e lucro é apresentada como a única possível, é abordado por Lacan (1974/1993) como uma modalidade degradada do discurso do mestre, que desestabiliza o laço social dominante na sociedade contemporânea. Tais atravessamentos e lógica não operam sem consequências para o sujeito. O discurso capitalista esclarece uma concepção

\footnotetext{
O termo gozo, introduzido por J. Lacan, passou por sucessivas modificaçôes e atualizações, enriquecendo a conceituação lacaniana do que está mais além do princípio do prazer freudiano e abrange, em sua relação com desejo, sexualidade ou Outro, vários sentidos. Neste trabalho, abordamos específicamente o gozo como dimensão mortífera para o desejo.
} 
de funcionamento social em que o indivíduo adapta-se a uma realidade dada. Privilegia não o sujeito, mas o indivíduo consumidor que, em sua dimensão de consumido, não encontra lugar para o seu pathos (sofrimento), para formular demandas, remetido que fica à colagem do objeto da demanda ao objeto do consumo. Outras estratégias societárias que não as instituídas são, no mínimo, desdenhadas e ridicularizadas para impedir a construção de "realidades" alternativas. O discurso do capitalismo produz uma espécie de anonimato de vida e de morte, efeito da desestabilização dos enlaçamentos sociais. Podemos mesmo afirmar que, na contemporaneidade, a experiência com o outro social se confunde com o exercício violento de emancipação do capital (Catroli, 2003).

De acordo com Guattari (1987), o modo de produção capitalista contemporâneo opera formas específicas de sociabilidade por meio de um duplo mecanismo que desestabiliza signos locais de reconhecimento sociais para reestruturá-los numa formação global hegemônica de poder. Em sua análise do capitalismo, ele afirma que, após colonizar todos os espaços geográficos possíveis, o capital é forçado a recompor-se internamente para continuar produzindo diferentes espaços para apoderar-se e continuar a expandir-se. Quando se esgota a possibilidade de expansão territorial para conquista de novos mercados, o capitalismo deverá, necessariamente, buscar crescer no próprio lugar. Assim, o movimento constante do capital deverá reinventar ao infinito os mesmos espaços. Este deverá reconfigurar-se e criar, num processo contínuo e ininterrupto, inúmeras figuras sociais, assim como diferentes especificidades para cada novo personagem. Essa incansável produção de novos territórios existenciais fomenta uma espécie de trânsito frenético por inúmeras possibilidades de afirmação subjetiva. Dessa forma, mesmo que admitamos que o discurso seja emitido por pessoas identificadas, estas funcionam como ventríloquos das vozes poderosas (anônimas) do mercado, um grande exército de subjetividades fast-food a constranger a resposta do sujeito dividido.

Esse discurso se alia ao discurso cientificista que, em suaânsia de objetividade, opta pela ausência do sujeito, correndo o risco de igualmente produzir ilusões e engodos, ao obturar o desejo pela certeza do $\mathrm{eu}^{2}$. O sujeito, convencido de que sua verdade é ilusão ou anacronismo e desestabilizado em suas insígnias, segue sem um projeto de futuro para si mesmo, seus filhos, sua comunidade: perde a direção de sua vida, adapta-se, debate-se para prosseguir.

Esse aspecto foi desenvolvido em outro artigo: Rosa, M. D., Carignato, T. T. \& Berta, S. Ética e política: a psicanálise diante da realidade e dos ideais contemporâneos. In: Ágora: estudos em teoria psicanalítica. IX (1). Rio de Janeiro: UFRJ; Contra Capa, 2006. 
Esses elementos compõem o germe da violência contemporânea, que, aparentemente desvinculado do discurso que a embala, comparece em outros lugares.

O sistema gera uma nova economia libidinal que exclui o pathos e substitui a demanda de amor pelo apelo ao consumo e ao lucro sobre o outro (Rosa, 2005). Lacan (1960/1991, p. 364) afirma que o serviço de bens tem exigências, e a passagem da exigência de felicidade para o plano político tem consequências. A questão é que não basta o acesso aos bens. Visa-se à destituição do outro, germe das violências com características peculiares de alimentarse no encobrimento, nas sombras do anonimato. $\mathrm{O}$ empuxo à destruição do outro não é motivado pelas propriedades do objeto odiado, mas aponta um real que transcende àquele para o qual se dirige a agressão. $O$ que se quer eliminar não é só aquele que está ali, mas o real, aquilo de insuportável e ingovernável que vem do real como o impossível de ser abarcado, representado, dominado, aquilo que aponta a castração.

Foi assim nos assassinatos de dez moradores de rua no Centro de São Paulo, em 2005. Os moradores de rua não obedeceriam a nenhuma regra de sociabilidade, ou seja, estariam além da governabilidade. Nessa medida, mostrando-se no real, os sem-teto aparecem como corpos fictícios, fora do tempo e do espaço. Não têm rosto, nome ou laço. Tais crimes revelam o triunfo sobre o outro, o orgulho de sua destruição, o gozo político do poder, gozo do faço porque posso. A audácia dos assassinos é comandada pela certeza da impunidade e por saberem que revelam o papel estrutural da violência no capitalismo. Diante dessa constatação, recorre-se a um artifício em que fica estabelecida uma distância entre cada um e os cidadãos assassinados e assassinos. Os primeiros, estigmatizados como vítimas, mendigos, párias, e os segundos, distanciados como assassinos ameaçadores: ambos confinados em um espaço imaginário que nos distancia deles, que nos põe como observadores externos ao acontecimento. Esse distanciamento é a estratégia alienante que nos salva da angústia de perceber que esses atos não são uma exceção que ocorre com alguns azarados ou praticados por algum bandido cruel, mas, ao contrário: nós, para sobrevivermos ao medo e à impotência, criamos uma suposta normalidade, uma ilha de ficção dentro de uma sociedade segregadora e bélica.

Pois bem: para vivermos numa ilha de ficção dentro de uma sociedade segregadora e bélica, precisamos viver como "sonsos essenciais", como diz Lispector (1971): "mantenho o conforto e a sensação de ser 'do bem". Ficamos na inocência, na indiferença mortal, no alívio indigesto e escondido de nós 
mesmos, pois, afinal, "alguém fez por mim, sujou as mãos por mim" ou "viveu por mim a raiva enquanto eu tive calma”. O medo, a impotência frente a uma realidade tida como imutável e o desejo de que minha casa funcione do mesmo jeito de sempre são os modos de sustentar uma impossibilidade de mudança. Dizendo eles, nós nos salvamos. Mas eles somos nós, e essa constatação encobre o terror da semelhança. Inventamos uma diferença radical entre nós e os personagens do massacre para contornar o medo. Sem querer saber o que se passa, embalados pela culpa e pela compaixão, postergamos o ato éticopolítico. E, se alguém o faz, é nomeado como radical, fanático, deslocado do seu tempo.

O caráter desencarnado, anônimo e abstrato daquele que enuncia o discurso (o mercado, o capital financeiro) tem efeitos para a dimensão da lei e da castração. A eficácia do anonimato pode ser verificada no caso dos assassinatos dos moradores de rua no Centro de São Paulo. Contribuiu para superdimensionar o medo, a impotência e a servidão. $\mathrm{O}$ anonimato dos moradores de rua e o de seus assassinos (livres na obscuridade e na certeza da impunidade, irmã da conivência) promove a corrosão das bases simbólicas da convivência. Tanto os sem-teto como os assassinos (nas sombras) não contam e não se contam entre os outros. Esse anonimato articula-se com outro: o dos beneficiários da concentração de renda e daqueles que anseiam por ocupar um lugar ao sol. Lugar atraente, sem dúvida, por duas razões: promove o esquecimento de que facilmente se vai para a calçada e ignora a realidade, não esperada, da perda da mercadoria que não cumpre o prometido fazer ser.

Nesse sistema, a história da comunidade não tem mais sentido. A pergunta feita por Hannah Arendt, da qual tomamos a expressão tempos sombrios, continua atual: "Como construir uma polis em que o homem - qualquer homem - não seja visto como supérfluo?” (1987, p. 241).

\section{O sentido da vida e as artimanhas do poder}

Um segundo aspecto das artimanhas do poder é incidir sobre o sentido da vida. As sociedades contemporâneas redefiniram, em nome da cultura, o significado da vida enquanto assinalam novas formas de poder que advém dessa operação, uma vez que a vida e o humano não são conceitos politicamente ingênuos. Duas formas do poder no contemporâneo investem sobre o sentido da vida: a discriminação entre o que é considerado civilizado ou monstruoso, ou seja, aquilo que é excluído de seu campo civilizador, e um modo particular de tratar o mundo natural que reduz a vida a sua modalidade orgânica e biológica. De modos distintos, autores de diversas áreas do conhecimento, como Lacan, Arendt, Foucault, Derrida e Agamben, convergem para 
demonstrar como o poder abala a potência da experiência compartilhada que escreve a história do sujeito e da comunidade 3 . Examinar esse aspecto fundamental permite indicar o caminho para um laço que permita constituir uma vida com o outro

A reflexão crítica de Arendt (1983) e posteriormente de Agamben (2002) toma a distinção grega entre zoé e bios. O homem grego conhecia duas palavras para designar vida: zoé e bios. A primeira dessas palavras expressava a vida que compartilhamos com outros seres vivos, uma "vida nua", natural, enquanto que apenas a segunda poderia indicar a vida civilizada, ou seja, vida humana propriamente dita, âmbito em que a questão política do bem viver poderia ser discutida.

O homem reduzido ao labor está voltado a assegurar as coisas necessárias à vida do corpo biológico. Tal homem encontra-se aprisionado, segundo Arendt, a uma atividade que se desenvolve de forma cíclica e repetitiva, que não termina senão com a exaustão da força de trabalho. Deixa de construir um mundo e de estar entre os homens como seres políticos e fica reduzido às necessidades privadas. Segundo a autora, o chamado "tempo livre" nesse modo de vida é gasto em consumir; e quanto maior é o tempo de que se dispõe, mais ávidos e insaciáveis são os apetites. O fato de que esses apetites se tornam mais refinados, de modo que o consumo já não se restrinja às necessidades da vida, mas, ao contrário vise principalmente às superficialidades da vida, não altera o caráter dessa sociedade. Além disso, acarreta o grave perigo de que nenhum objeto do mundo estará a salvo do consumo e da aniquilação pelo consumo (Arendt, 1983, p.146).

Giorgio Agamben (2002), partindo da mesma distinção da concepção de vida, enfatiza a preponderância da vida nua, afirmando que o regime contemporâneo exerce um poder sobre a vida que, travestido de defesa da vida, a reduz à sua modalidade biológica. É precisamente a politização da $z o e$, de acordo com as determinaçôes da lógica do mecanismo industrial, que marcaria a sociabilidade moderna. A inserção da vida natural no centro das estratégias políticas do mundo ocidental, fenômeno que consolida e define a acepção moderna de exercício do poder, retoma e atualiza aquilo que Michel Foucault chama de biopolitica ${ }^{4}$. No $A$ Vontade de saber, ele já chamava a atenção

\footnotetext{
Destacamos, neste artigo, o ponto de convergência, especialmente ético-político, entre esses autores. Fica registrado que, em outros aspectos relevantes dessas teorias, encontramos divergências expressivas, a começar da noção de sujeito e subjetividade, entre outros.

Foucault, ao cunhar o termo biopoder buscava discriminá-lo do regime que o havia precedido, denominado de soberania. O regime de soberania consistia em fazer morrer e deixar viver. Já no contexto biopolítico, não cabe ao poder fazer morrer, mas, sobretudo, fazer viver, isto é, cuidar da população, da espécie, dos processos biológicos, otimizar a vida. O poder
} 
para essa transformação cultural radical. A vida (humana e não humana) que, segundo estruturas modernas pode moldar, estender, potencializar, higienizar, distribuir no espaço e transformar de acordo com a lógica do mecanismo industrial, precisa ser pensada como uma vida esvaziada de conteúdos culturais e, portanto, passível de racionalização. $\mathrm{O}$ capitalismo industrial treinou, aumentou e potencializou a vida útil desses corpos. Trata-se não apenas de disciplinar um homem-corpo pensado como inteireza, individualidade, mas da regulamentação da vida humana, de exercer um controle sobre a vida pensada em bloco, sobre o ser humano concebido como ser-espécie (Foucault, 1993, p. 298-299).

Destacamos as formas do poder no contemporâneo que investem sobre o sentido da vida, apontadas por Agamben (2002), que alerta sobre a redução da vida à sua modalidade orgânica e biológica, e por Arendt (1983), que mostra como todas as atividades humanas foram reduzidas ao labor. A eficácia dessa forma de poder depende do abalo da experiência compartilhada.

De modos diversos, os autores convergem para demonstrar como o poder abala a potência da experiência compartilhada que escreve a história do sujeito e da comunidade. Agamben (2002b) apresenta no livro Lo que queda de Auschwitz, a figura dos musulman (os mortos-vivos) para debater a noção de campo como paradigma do social no contemporâneo, modalidade de organização positivada a partir da supressão do ordenamento jurídico, que produz, a partir da lógica de exceção, sujeitos legalmente inomináveis. O espaço do campo é o que emerge nessa área de exceção e o que fará a interseção entre o dentro e fora do ordenamento. Catroli (2003) demonstra como as modulaçôes na ideia de campo caracterizam o capitalismo global e se efetivam em amontoar em guetos e favelas todos aqueles que se constituem o refugo vivo do nosso tempo.

Nesse livro, o autor colocará em cena a figura da testemunha e do musulman, dois modos de subjetivar na mais absoluta dessubjetivação dos campos de extermínio nazista. Da testemunha, muitas vezes se ouviu que seu objetivo de sobreviver ao campo era movido pela certeza de poder contar ao mundo o que ali se passava e que o impossível tinha ganhado forma. Já a figura do musulman constituía a emblemática do estado limite a que chegaram algumas pessoas nos campos de concentração (Rosa \& Poli, 2009). Do musulman, aquele que diante da corporificação do impossível nada podia fazer senão calar. Os

investe a vida, não mais a morte; daí o desinvestimento da morte, que passa a ser anônima, insignificante. Para Agamben, a ambição suprema do biopoder é realizar no corpo humano a separação absoluta do vivente e do falante, de zoé e bios, do não homem e do homem: a sobrevida. A sobrevida é a vida humana reduzida ao seu mínimo biológico, à sua nudez última, à vida sem forma, ao mero fato da vida, à vida nua (Pelbart, 2003). 
musulmans só puderam ser contados graças ao testemunho daqueles que, diante do horror, narraram. E, dessa forma, muitas vezes foram descritos como aqueles que viviam no umbral entre a vida e a morte, entre o humano e o desumano, que não tinham esperança, não mais se sensibilizavam como os outros, não se solidarizavam com o trabalho necessário ou estavam demasiado vazios para sofrer. Esses, que não eram considerados semelhantes e que eram evitados por conter o homem no não homem. Enquanto que o sobrevivente, a testemunha, esse em especial, "tem a vocação da memória, não pode não recordar" (Agamben, 2002b, p. 25).

Os musulmans só despertavam a ira naqueles que, na mesma situação, procuravam a vida e não a morte lenta. Os que puderam testemunhar sentiam ira, pois os musulmans eram portadores de um futuro que os incluía, já que sabiam que podia se tratar apenas de uma questão de tempo até sucumbirem. Os musulmans eram aqueles que causavam estranheza.

Esse modo de existência, subtraída de qualquer possibilidade de laço com o outro, pode expressar certo destino dos sujeitos da contemporaneidade, exilados que estão de sua identidade, em um não-lugar em relação ao semelhante. $\mathrm{O}$ musulman lembra os sujeitos excluídos na realidade social brasileira (Rosa \& Poli, 2009). Esses não habitam os campos de concentração ou de extermínio do nazismo, mas se movimentam e vivem de acordo com os interesses do capital, nos espaços pauperizados das periferias e das favelas das grandes cidades. Estão mais próximos de serem os estranhos, aqueles que, a partir das consideraçôes de Freud (1919/1972), carregam a possibilidade de trazer à tona o que deveria permanecer oculto. Esses que deverão, sempre, estar circunscritos num espaço de visibilidade/invisibilidade, para que não denunciem (com sua presença, já que lhes é negada a possibilidade de narrativa) o furo, a lacuna que reside em todo ato de governar e de regular as civilizações. Os estranhos são a prova. São aqueles que o capitalismo contemporâneo deverá apagar, fazer calar, ao produzir a ilusão de que estão mortificados, anônimos, imersos num cenário desértico da mais completa dessubjetivação do socius (Catroli, 2008). Apagamento e mortificação sobre a vida, que resulta na sobrevida, mas que a potência política $d a$ vida também reinventa em outras estratégias de resistência: é o caso das rebeliōes dos jovens nos internatos que lançam seus corpos nus, esse mínimo que lhes resta, numa estratégia hiper-realista de vida - uma espécie de experiência existencial, direta, concreta, dramática e corpórea da realidade - que evidencia um poder de inventar-se a si mesmos numa linha de fuga da captura social (Vicentin, 2005).

Essas estratégias de poder nos permitem examinar como se constrói a perda da experiência compartilhada e permitem indicar o caminho para um laço que constitua uma vida própria com o outro. Visando a um vocabulário conceitual para 
articular as influências da globalização e as disposições pessoais, Guidens (2002, p. 148) descreve a segregação da experiência como

Os processos de ocultação que separam as rotinas da vida ordinária dos seguintes fenômenos: loucura, criminalidade, doença e morte; sexualidade e natureza [...]. - E ainda - [...] $\mathrm{O}$ argumento que desenvolvo é que a segurança ontológica que a modernidade adquiriu, no nível das rotinas diárias, depende de uma exclusão institucional em relação à vida social de questôes existenciais fundamentais que apresentam dilemas morais centrais para os homens.

Demonstra ainda que facetas humanas que possibilitem criar um sentido para a vida ficam excluídas da vida, e esta reduzida a um cotidiano amorfo.

Agamben (2004) questiona a atual substituição da experiência pelo conhecimento na contemporaneidade. Considera que as constataçóes de que o homem não é desde sempre falante e que tenha tido uma infância (tomada como o inconsciente) explicitam o limite da linguagem, de modo que esta não possa apresentar-se como a totalidade e a verdade última do sujeito. Experimentar significa necessariamente voltar a acionar o infantil como pátria transcendental da história, diz o autor, afirmando que "a infância do homem é o lugar da experiência" (p. 66). Ao propor uma articulação da infância com a distância necessária para a experiência e o registro da história, deixa claro que as questóes desse debate transcendem o campo ideológico e dizem respeito ao campo da ética e da política.

De outro modo, Ortega (2002) demonstra que o declínio da amizade nas sociedades contemporâneas estáligado aos processos de despolitização efamiliarização do privado, como a amizade foi desaparecendo do espaço público e deslocando-se para a esfera privada e doméstica, sendo posteriormente integrada à família nuclear. A crise da instituição familiar na década de 1960, como instituição social e econômica, não contribuiu para diminuição de sua força ideológica que vê na família a cura das mazelas sociais. Esta se mantém como ideal de felicidade e normalidade que despreza outras formas de relação, pois, supostamente, estas não dariam segurança psíquica e suporte material, enfurnados no espaço privado. Assim, o processo de despolitização, de esvaziamento do espaço público da modernidade, acompanha a progressiva familiarização do privado que desfavoreceu as sociabilidades públicas e a amizade.

O desafio do homem contemporâneo versa sobre como contrapor outras formas de expressão da vida para além desta que nos torna seres privados tanto da presença dos outros como da realidade que advém de um mundo compartilhado. 


\section{A experiência, a amizade e o riso. "E agora, José?"5}

E agora, José? A festa acabou

a luz apagou

o povo sumiu

a noite esfriou, e agora, José?

e agora, você?

Você que é sem nome, que zomba dos outros, você que faz versos, que ama, protesta?

E agora, José?

Está sem mulher,

está sem discurso, [...]

a noite esfriou,

o dia não veio,

o bonde não veio,

o riso não veio,

não veio a utopia

e tudo acabou, [...]

E agora, José? [...]

Se você gritasse,

se você gemesse, [...]

Sozinho no escuro

qual bicho-do-mato,

sem teogonia, [...]

sem cavalo preto

que fuja do galope,

você marcha, José!

José, para onde?

(Andrade, 1942, grifo nosso)

A estratégia política de controle e submissão no mundo contemporâneo enreda o sujeito em seu campo libidinal. Diante da impossibilidade prometida de uma relação sem embaraço com o outro, o sujeito enreda-se no gozo, seja insistindo nessa direção, seja entregando-se, tal qual Drummond dramatiza, com o personagem José, ao ressentimento e à amargura, entre outras muitas manifestações. A impossibilidade veda a persistência, concomitante ao poder sobre a vida, de outras dimensóes em que o desejo comparece e, ainda que

\footnotetext{
Referente à poesia José, de Carlos Drummond de Andrade.
} 
fugaz, redireciona e reinventa formas de viver. Retomar a vida como bios supõe o deslocamento do gozo monitorado politicamente e mortífero para o desejo, para uma práxis caracterizada pelo resgate da experiência compartilhada do mundo; supõe a presença dos laços de amor e amizade que fazem ruir alegremente as grades opressoras do poder soberano.

Indicar algumas vias de resgate da dimensão do desejo foi a tarefa de Freud. Ele demonstra que é no campo intersubjetivo conceituado como campo transferencial que se produz o saber do sujeito: sujeito do desejo, engendrado pela cultura, mas que, em sua condição de dividido, pode transcender o lugar em que é colocado e apontar na direção de seu desejo. E é nesse campo compartilhado que o sujeito faz a experiência de inventar-se e inventar o mundo.

O caráter constituinte e antecipatório da experiência é demonstrado na psicanálise quando Lacan (1962-1963/2005, p. 41) diz que, quando a criança, "capta-se na experiência inaugural do reconhecimento no espelho, assume-se como totalidade que funciona como tal em sua imagem especular [...] a criança se volta, [...] para aquele que a segura e que está atrás dela”. Esse movimento invoca o Outro para que ratifique o valor dessa imagem. Estão aí indicados os registros do imaginário, do simbólico e do real que compõem essa e qualquer outra experiência fundante.

Outro aspecto da experiência abordado por Freud e, posteriormente, por Lacan (1964/1979), é a experiência via da repetição. Para isso, Lacan se valeu da tradição mítica grega da fortuna, tiquê, articulando-a ao automaton. Enquanto o automaton aponta para a repetição sintomática, como insistência dos signos comandada pelo princípio do prazer, a tiquê indica esse encontro do real, que vige sempre por trás do automaton, para além do princípio do prazer. O termo tiquê indica o encontro meramente casual, contingente, fortuito, o encontro faltoso com o Real, no qual o "objeto perdido da história de cada sujeito, objeto $a$, pode ser reencontrado nos sucessivos substitutos que o sujeito organiza para si em seus deslocamentos simbólicos e investimentos libidinais imaginários. Mas, nesses reencontros, por trás dos objetos privilegiados de seu desejo, o sujeito irá deparar-se de forma inarredável com a Coisa perdida da espécie humana: isso significa que se trata sempre, nos reencontros com o objeto, da repetição de um "encontro faltoso com o real" (Jorge, 2005, p. 142).

Assim, em vez de adaptação à realidade, do encontro pleno, sem embaraço ou pathos, a psicanálise enfatiza o encontro com o real pulsional, traumático, pois constata que o objeto do desejo não existe na realidade, que não há um sentido estabelecido para a vida. Só vazio. Não há como responder ao "Che 
vuoi?" (o que o outro quer?). O sujeito ofuscado pela imagem de si estremece no encontro com o real, pois depara a sua condição trágica. No desejo está a verdade do sujeito. "Mas o sujeito é um vazio sem autor, e seu desejo é uma falta-a-ser. É preciso haver um ato de assentimento ao nada e instaurar um lugar vazio, quando, então, a morte passa a sustentar a vida. Só a certeza do fim possibilita suportar esta história” (Rosa, Carignato, Berta, 2006, p. 46).

O lugar vazio no Outro não enuncia a lei. Cabe, pois, ao sujeito, enunciála e tomá-la como esteio que determina o lugar do gozo. Desse modo, "cada um, cada uma, é responsável por seu inconsciente e pela Lei que nele se articula... É esse o móbil de nossa interrogação sobre a Lei: de fato, longe de ser uma simples negação privativa, ela deve ser uma borda que sirva de apoio" (Julien, 1996, p. 94). Clarice Lispector vem nos lembrar de que arrebentar um modo de viver não é arrebentar tudo quando diz: "Eu devo ter esquecido que embaixo está o terreno, o chão onde nova casa poderia ser erguida." (Lispector, 1971).

Além dessa condição primordial para a invenção de si mesmo, há outras como a sublimação, com o seu vínculo com a arte e a criação. Mas salientaremos aqui o chiste $^{6}$ como mais um desses instrumentos. $\mathrm{O}$ chiste na obra de Freud assume o lugar de uma formação do inconsciente, caracterizado pelos mesmos mecanismos de condensação e deslocamento presentes nos sonhos e nos lapsos. A economia do chiste gira em torno do prazer, ligado a uma satisfação pulsional; o chiste é o disfarce que as pulsões encontram para driblar o recalque. O chiste gera uma espécie de alívio no sujeito ao livrá-lo de algo que estava suprimido ou inibido. Isso vale para quem o faz, mas também para quem o escuta, por reconhecer-se no que é dito pelo outro.

Escrevendo sobre o chiste e os sonhos, Freud (1905/1972) diz que o sonho é um desejo irreconhecível, e o chiste, um jogo que, diferente do manejo perverso que promove angústia no outro, tem a função de dissolver recalques, desdramatizar o sofrimento. Assim, se o sonho encaminhase predominantemente para evitar o desprazer, o chiste visa à obtenção de prazer. E, importante ao nosso tema, enquanto o sonho é totalmente associal, "O chiste é a mais social de todas as funções anímicas encaminhadas para a obtenção do prazer. Precisa de três pessoas, e o seu aperfeiçoamento requer a participação de um estranho nos processos anímicos por ele estimulados"

\footnotetext{
Witz, chiste em alemão: segundo Midlej (2005), na tradução brasileira utilizou-se chiste, palavra emprestada do castelhano, que quer dizer dito gracioso, pilhéria; em francês quer dizer mot d'esprit ou esprit simplesmente. Jacques Lacan (1999), no seminário "As formaçōes do inconsciente", propôs o que ficou traduzido para o português como tirada espirituosa. Seguindo essa linha de tradução sugerida por Lacan, tornou-se comum encontrarmos em textos brasileiros de psicanálise a expressão dito espirituoso.
} 
(Freud, 1905/1972, p. 193). O chiste pode representar uma rebelião contra uma autoridade e se presta a atacar os grandes e poderosos: pela mediação do terceiro (aquele que escuta), como também da palavra cifrada ou engenhosa do chiste, o alvo fica protegido de uma hostilidade direta. $\mathrm{O}$ chiste tem a função de livrar-nos de uma pulsão agressiva, ao destituirmos o outro, que nos parece ameaçador; e, muitas vezes, tem a função de livrar-nos de uma mentira ou, em última instância, de uma culpa.

O chiste traz uma marca de criatividade e inclui o outro, quer queira ou não, como parceiro e testemunho do que irrompe graças ao deslocamento das defesas, abrindo novos canais de circulação. É experiência de transgressão, de expressão direta do que está velado na relação com o outro: o chiste supera os limites do recalque. Vinte anos mais tarde, Freud (1927/1972) escreveu um artigo exclusivamente dedicado ao humor, escrito sob a égide da segunda tópica freudiana, considerando o conceito do supereu, no caso, um supereu protetor, que permite ao eu evitar o sofrimento e servir-se do prazer que o humor pode dar.

O discurso freudiano foi forjado, afirma Birman (2005, p. 92), "Pelo contraste entre o chiste e o drama, pelo deslocamento de um para outro registro; portanto é fundamental destacar como a psicanálise se iniciou pela oposição entre estas polaridades do pathos". O deslocamento do pathos do registro do drama para o do trágico convida para a experiência e para a construção de instrumentos para o sujeito lidar com a tragicidade inerente à condição humana. Freud finaliza seu texto dizendo: "Significa: Olhem! Aqui está o mundo, que parece tão perigoso! Esse mundo não passa de um jogo de crianças, digno apenas de que sobre ele se faça uma pilhéria" (Freud, 1927/1972, p. 194).

José, o personagem acima citado de Drummond, não teve o pai de José Luís, como nos conta Galeano (2002, p. 215): "E, de tudo o que José Luís aprendeu com seu pai, isso foi o principal:

- O importante é rir - ensinou-lhe o velho - E rir juntos”.

Há um componente ético que toca a medida da ação ou a "dimensão que se expressa no que se chama experiência trágica da vida. É na dimensão trágica que as ações se inscrevem e que somos solicitados a nos orientar em relação aos valores" (Lacan, 1960-1970/1992, p. 376). Relacionando trágico e cômico, no fracasso fundamental da relação da ação com o desejo, Lacan nos lembra de que o que nos faz rir na comédia é o fato de a vida escorregar, escapar a tudo que se lhe põe como barreira; essa é a experiência da ação humana. 
Demonstramos como a experiência compartilhada é um dos instrumentos de resistência às estratégias do poder; é ato de transgressão, de superação dos limites, de revelação da impostura. Esta tem poder, poder de denunciar e mesmo de contornar as identificaçôes imaginárias presentes nas diversas formas de manifestação do ódio ao outro, dos racismos; de transformar a agressão mortífera em chiste e gozar com o riso que propicia barrar a identificação com o agressor e esvaziar, em ato, na cena social, o aniquilamento presente no gesto racista (Birman, 2005). Restaura uma potência irreverente e um desejo de transgressão, ambos presentes no sujeito. Revela o seu poder e permite ao sujeito afirmar seu desejo e restaurar direitos. O humor é uma das formas criativas de reação ao discurso discriminatório, um modo de não incorporar a crueldade e não ficar preso a uma mortificação passiva.

O ponto em questão (estratégias para a construção de laços que permitam a experiência compartilhada) nos lança para concluirmos no tema dos laços com os contemporâneos, enunciada na epígrafe. Ortega (2002) ressalta que o processo coletivo nos livra da "tirania da intimidade", que não permite o cultivo de uma distância necessária para a amizade. A reabilitação do espaço público permite que uma amizade seja um experimento social e cultural plausível para a construção de projetos comuns, para a construção de utopias. O espaço da amizade é o espaço que torna o mundo compartilhado, espaço da liberdade e do risco.

Nessa direção, está a consideração da função e potência da fratria, desenvolvida por Kehl (2000), que examina a função fraterna. Kehl aponta que a experiência com os limites amparada pelo grupo, e não solitária, tem duas consequências importantes para o sujeito.

Primeiro, a diminuição da ameaça e da culpa que pode pairar sobre cada um, isoladamente. Lembremo-nos mais uma vez de que, conforme a dimensão da desobediência civil coletiva, até mesmo uma nova ordem social pode ser fundada. Segundo, a experiência compartilhada permite a troca de impressões e reflexões sobre o vivido que contribuem para alterar o campo simbólico, já que questionam verdades tidas como absolutas pela cultura (p. 41).

Concluímos este artigo registrando que, ao intensificarmos e mobilizarmos nossas redes de relaçôes, podemos tocar o desejo, vetor da cena lúdica e coletiva, de modo a reinventarmos o sexual, o social, o político. A pergunta da epígrafe, "quem são os meus contemporâneos?" recoloca-se e articula-se à resposta de Juan Gelman segundo a qual as redes, sustentadas pelo desejo, são orientadas por uma lógica própria que faz com que traços como $o$ inefável do 
rumor do pente em seus cabelos seja aquilo que une a mulher ao pastor de cabras, este ao chinês, este a Juan Gelman, a Galeano, a mim, a você. Concordamos com Costa e Fonseca (2007, p. 119) quando, sintônicos com a proposição do poeta, podemos dizer que:

Ser contemporâneo é afundar-se na rede, nos seus tempos diversos, investigar estilos esquecidos e trazê-los à tona em sua estranheza rétro (nada mais contemporâneo do que algo rétro) para compor novas variações sem apego a suas formas tradicionais. Assim, em vez de estarà frente do seu tempo, o contemporâneo habita a conjunção dos diversos tempos que constroem seu instante, buscando uma customização temporal a partir desta heterogeneidade flexível e singular. Perambula-se mais pelas tramas virtuais da rede temporal, complexificando as tendências de atualização. Pois, é visibilizando pelo estranhamento a rede de relações de saberpoder que constroem nosso tempo, que conseguimos não apenas compreender as condiçốes de possibilidade que lhe dão suporte, mas também abrir o campo de possibilidades de reinvenção dos arranjos de fluxos que constituem nossa atualidade.

Eis do que se trata: reinventar a vida, criar mecanismos de pressão contra a submissão ao poder soberano e resgatar a experiência compartilhada com os amigos, enfim, com os contemporâneos.

\section{Referências}

Agamben, G. (2002). Homo sacer: o poder soberano e a vida nua. Belo Horizonte: UFMG.

Agamben, G. (2002b). Lo que queda de Auschwitz: el archivo y el testigo Homo Sacer III. Valencia: Pre-textos.

Agamben, G. (2004). Infância e história: ensaio sobre a destruição da experiência. Buenos Aires: AH Adriana Hidalgo.

Andrade, C. D. de. (1942). José. In: Poesias. Rio de Janeiro: José Olympio. Recuperado em 20 de março, 2009, de http://www.memoriaviva.com.br/ drummond/poema022.htm.

Arendt, H. (1983). A condição humana. Rio de Janeiro: Forense Universitária.

Arendt, H. (1987). Homens em tempos sombrios. São Paulo: Companhia das Letras. 
Birman, J. (2005). Frente e verso: o trágico e o cômico na desconstrução do poder. In: Slavutzky \& Kupermann (orgs.). Seria trágico se não fosse cômico. Rio de Janeiro: Civilização Brasileira.

Catroli, V. S. (2008). Anonimato de vida e de morte: figuras contemporâneas de uma trama social violenta. Submetido para publicação.

Catroli, V. S. (2003). A lógica do controle global e sua estranha imanência: o caso do Brasil e a emergência de uma norma violenta de sociabilidade. Dissertação de mestrado, Departamento de Psicologia, Universidade Federal Fluminense, Niterói.

Costa, L. A. \& Fonseca, T. (2007). Do contemporâneo: o tempo na história do presente. Arquivos Brasileiros de Psicologia, 59 (2), 110-119.

Foucault, M. (1993). História da sexualidade I: a vontade de saber. Rio de Janeiro: Graal.

Freud, S. (1972). O chiste e suas relações com o inconsciente. In: S. Freud. Edição standard brasileira das obras completas de Sigmund Freud. V.8. Rio de Janeiro: Imago. (Texto original publicado em 1905).

Freud, S. (1972). O estranho. In: S. Freud. Edição standard brasileira das obras completas de Sigmund Freud. V.17 (pp. 275-314). Rio de Janeiro: Imago. (Texto original publicado em 1919).

Freud, S. (1972). O humor. In: S. Freud. Edição standard brasileira das obras completas de Sigmund Freud. V.21 (pp. 189-194). Rio de Janeiro: Imago. (Texto original publicado em 1927).

Galeano, E. (2002). O livro dos abraços. (9a ed.). Porto Alegre: L\&PM.

GuattarI, F. (1987). Revolução molecular: pulsações políticas do desejo. São Paulo: Brasiliense.

Guidens, A. (2002). Modernidade e identidade. Rio de Janeiro: Jorge Zahar.

Jorge, M. A. C. (2005). Fundamentos da psicanálise de Freud a Lacan. Rio de Janeiro: Zahar.

Julien, P. (1996). O estranho gozo do próximo: ética e psicanálise. Rio de Janeiro: Zahar.

Kehl, M. R. (org.). (2000). Função fraterna. São Paulo: Relume Dumara. 
Lacan, J. (1979). O seminário: livro 11: os quatro conceitos fundamentais da psicanálise. Rio de Janeiro: Zahar. (Texto original publicado em 1964).

Lacan, J. (1991). O seminário: livro 7: a ética da psicanálise. Rio de Janeiro: Zahar. (Texto original publicado em 1960).

Lacan, J. (1992). O seminário: livro 17: o avesso da psicanálise. Rio de Janeiro: Zahar. (Texto original publicado em 1969-1970).

Lacan, J. (1993). Televisão. Rio de Janeiro: Zahar. (Texto original publicado em 1974).

Lacan, J. (2005). O seminário: livro 10: a angústia. Rio de Janeiro: Zahar. (Texto original publicado em 1962-1963).

Lispector, C. (1971). Mineirinho. In: C. Lispector. Felicidade clandestina. (pp. 75-81). Rio de Janeiro: Rocco.

Midlej, E. (2005). O chiste na sua dimensão clínica e ética. (Submetido para publicação).

Ortega, F. (2002). Genealogias da amizade. São Paulo: Iluminuras.

Pelbart, P. P. (2003). Poder sobre a vida, potências da vida. In: P. P. Pelbart. Vida capita: ensaios de biopolítica. (pp. 19-27). São Paulo: Iluminuras.

Rosa, M. D. (2006). Gozo e política na psicanálise: a toxicomania como emblemática dos impasses do sujeito contemporâneo. In: Ana Maria Rudge, (Org.). Traumas. (pp.101-111). São Paulo: Pulsional.

Rosa, M. D., Carignato, T. T. \& Berta, S. (2006). Ética e política: a psicanálise diante da realidade e dos ideais contemporâneos. Ágora: Estudos em Teoria Psicanalítica, 9(1), 35-48.

Rosa, M. D. \& Poli, M. C. (2009). Experiência e linguagem como estratégia de resistência. Submetido para publicação.

Vicentin, M. C. G. (2005). Vida em rebelião: jovens em conflito com a lei. São Paulo: Hucitec. 